\title{
Antecedents of Success Rate of Award-Based Crowdfunding: The Case of the "Kickstarter"
}

\author{
Chang Liu, Jinshan Liu \\ School of Economics, Jinan University, Guangzhou, China \\ Email: sxdtlc0329@126.com
}

Received 14 February 2016; accepted 19 March 2016; published 22 March 2016

Copyright (C) 2016 by authors and Scientific Research Publishing Inc.

This work is licensed under the Creative Commons Attribution International License (CC BY). http://creativecommons.org/licenses/by/4.0/

\section{(c) (i) Open Access}

\begin{abstract}
Based on the previous studies, this paper applied the theoretical elaboration likelihood model to the in-depth analysis of psychological path of the investors when they made a final investment decision after browsing and screening relative information of award-based crowdfunding projects. Then this paper studied the influence of various factors on the success rate of the crowdfunding projects. Logistics method was chosen for empirical verification based on selected detailed data on 300 Chinese items on Kickstarter platform; the results showed that the central clue: the ambiguous degree of the description, the key word of risk, the update, and the peripheral clue: initiator's social capital, the duration of the project were positively related to the success rate of crowdfunding. It was proved that investors would make rational investment decisions when facing high uncertainty characteristics of the target projects.
\end{abstract}

\section{Keywords}

Component, Award-Based Crowdfunding, Success Rate of Financing, Theoretical Elaboration, Likelihood Model

\section{Introduction}

Mollick [1] (2012) defined crowdfunding as: crowdfunding allows founders of for-profit, artistic, and cultural ventures to fund their efforts by drawing on relatively small contributions from a relatively large number of individuals using the internet, without standard financial intermediaries. Every investor can get physical objects (such as expected products) or equity returns in return for a small amount of investment amount. Crowdfunding is conducive to long-tailed innovation, the startup projects which were ignored by the $\mathrm{VC}$ funds before they are able to fund their efforts via crowdfunding platforms.

Crowdfunding has developed rapidly since 2009. The funders have extended from geek to the general public with the popularity of the internet financial concept. Reward-based crowdfunding funders face the situation of 
"all or nothing" or threshold model. The funder's pledge money is only collected if the goal is reached within the financing duration. Funders either receive a reward for backing a project or bear loss if the project fails [2]. Funders face a great risk.

This paper explores the psychological path of crowdfunding funders throughout the process of browsing the project information and making investment decisions; classifies different kinds of information like uncertainty of project information, risk warnings and the social capital established in the platform community to central cues information and peripheral cues information; examines how the two types of information affect the investment decisions of funders and the success rate of the project. This paper verifies the related hypothesis via the empirical results based on the selected detailed data on 300 Chinese items on Kickstarter platform.

\section{Literature Review}

\subsection{Crowdfunding}

The concept of crowdfunding evolved from crowdsourcing, a term first coined as "the act of a company or institution taking a function once performed by employees and outsourcing it to an undefined (and generally large) network of people in the form of an open call". Companies can obtain ideas, feedback, and solutions from their customers and business partners through crowdsourcing mechanisms. In addition to collecting creative business ideas and solutions, crowdsourcing can be used to tap peoples' excess capacities and resources, such as monetary and financial resources. This type of crowdsourcing where customers serve as investors is called crowdfunding. Crowdfunding is an effective funding channel for obtaining small- to medium-sized investments from the crowd.

In the current study, we focus on reward-based crowdfunding, which is defined as "crowdfunding involves an open call, essentially through the Internet, for the provision of financial resources either in the form of a donation or in exchange for some form of reward and/or voting rights in order to support initiatives for specific purposes". This definition of crowdfunding does not cover other models, such as lending-based crowdfunding and equity-based crowdfunding.

\subsection{The Study of Financing Incentives and the Mechanism of Crowdfunding}

Gerber et al. (2012) [3] originated in crowdfunding incentives analysis from the perspective of behavioral science and human-computer interaction, and mainly focused on the positive incentive description on both sides of crowdfunding sponsors and funders. He qualitatively explored that the enthusiasm of funders were derived from product consumption, the social identity of personal value and the altruism of innovation spirit. Crowdfunding creates new social interaction by means of stimulating the public to participate in crowdfunding, in this way, crowdfunding participators with similar interests and ideals resonate with each other and feel sense of belonging in the community created by the crowdfunding platform. Agrawal et al. (2013) [4] further studied the three-part bidirectional incentives of crowdfunding, and put forward but not validate the mechanism of crowdfunding from the perspectives of basic economics theory, which is derived from incentives and market failure theory analysis. Ling Huang and Qin Zhou (2014) [5] combined financing incentives with mechanism design of crowdfunding and made detailed theoretical analysis on the heterogeneity of the three-part bidirectional incentives of crowdfunding from the perspective of industrial organization theory. They pointed that the role of crowdfunding platform could connect the heterogeneous incentives of the sponsors and the funders. The perfectly designed mechanism would turn the three-part bidirectional incentives into positive feedback effect which led to successfully funded project.

\subsection{The Study of Antecedents of Success Rate of Crowdfunding}

The antecedents that have been previously studied are: project quality, the individual social capital, the regional social capital and the human capital of the sponsor. Giudici (2012) [6] divided social capital into individual social capital and regional capital from the perspective of personal exclusive and regionally sharing. His study results showed that individual social capital is positively related to crowdfunding success. The studies of Agrawal et al. (2011) [7] showed that regional social capital is positively related to the success of project financing for that funders mainly come from the nearby geographical area. Mollick (2014) [8] argued that the number of sponsors' facebook fans should be an important indicator of measuring the social network of sponsors, and the 
project quality, the social network, the regional factors and project type are the important factors that affect project success rate, based on the data analysis of 48,500 projects on Kickstarter.

Funders make investment decision about whether or not supporting a crowdfunding project after browsing related information could be understood as a process of attitude change. To explore how the investors select and analyze project information from the angle of psychology is comparatively less studied by domestic and foreign scholars.

In this paper, firstly I used the experience of the predecessors and analyzed the psychological path of the investors when they browsed and filtered relative information and eventually made investment decisions based on the theory of elaboration likelihood model, then this paper studied the influence of various factors on the success rate of the crowdfunding projects.

\section{Theory and Hypotheses}

\subsection{The Theory of Elaboration Likelihood Model}

The psychologists Petty and Cacioppo (1986) [9] put forward ELM (which is short for Elaboration Likelihood Model). It is the most influential theoretical model in consumer information processing, which explains two special persuasion methods when individuals process cognitive information. The model argues that there are two basic paths for the change of attitude: central route and peripheral route. The central route includes information elaboration processing-an individual's consideration degree on the argument that includes persuasion and is related to the event (Petty and Cacioppo, 1986). When individuals choose to do information processing with the peripheral route, consumers' changing attitude to the object does not lie in their consideration of the features or evidence of the object but link the object with other factors. Petty and Cacioppo (1986) argued that the choice of central route or peripheral route depended on two key factors: one was that whether information receivers had the motive of elaboration processing; the other was receivers' information processing ability (consumers' cognitive level and cognitive environment).

The change of attitude caused by the central route would last a longer time than that of the peripheral route. But peripheral route has an important influence on the change of mind. Both the former and the latter could not be the only reason for the diversified results of attitude change (Martin and Hewstone, 2010) [10]. Consumers desire to seek for and process information under some circumstances. However, they would avoid when facing the complicated cognitive activities under the other situations (Li Zhong and Ma Jing, 2006) [11]. These two paths could be transformed with each other (Petty and Cacioppo, 1986).

\subsection{Product Crowdfunding Investors' Mental Path Choice in Investment Decision}

The current researches on consumers' motive in crowdfunding show that the motives include the strong cognitive value of pre-sale products, and the mind that satisfying the investors with higher payment will (Huang Ling and Zhou Qin, 2014). Investors must be extremely interested in the project before investing. The fund for investment has to pay the opportunity cost during the financing period due to the threshold mechanism "all or nothing"on the crowdfunding platforms (Agrawal et al. 2015) [12]. Therefore, the potential project investors must have strong motive to elaborately process the concrete information of the project on the crowdfunding platforms.

Investors will choose the central route at first to deal with project information under the situation with the high degree of involvement and the strong motive. The paper proposes the following proposition:

Proposition 1: Investors will choose the central route at first to deal with project information under the situation with the high degree of involvement and the strong motive.

The quality of information elaboration processing also rests on investors' ability of information processing. All projects on crowdfunding platforms are innovative ones, and investors tend to be attracted by the creative ideas when browsing information, but they may lack the relevant knowledge. Take the Chinese project- "Air umbrella" in the smart hardware board on Kickstarter as an example. The project is novel, but the introduction is limited and many affairs are still in planning, so it will be hard for the investors without the relevant background knowledge to judge whether the project is feasible and there will be no persuasive evidence to support the investment decision. However, from the perspective of its crowdfunding result, 825 supporters successfully raised 102,240 dollars for this project within 30 days, which exceeded the sponsor's original goal-10,000 dollars. The result showed that under the circumstance when project description is vague and investors only have the limited 
information, many investors with great interest will focus on other relevant factors-they will take the peripheral route to make investment decisions.

Investors usually take the peripheral route to make simple deduction and judgment with the help of features of communication environment and situation factors under the circumstance when the argument is not persuasive nor evidence is lacked. For example, sponsors and supporters could communicate information abundantly and transparently on the communication platform built by crowdfunding platforms. Therefore, the paper proposes the following proposition:

Proposition 2: Some investors will choose the peripheral route to make decisions under the situation when crowdfunding projects are uncertain and investors have the limited cognitive ability.

\subsection{Analysis on Influence Factors of Decision of Product Crowdfunding Investors}

Most of sponsors on crowdfunding platforms are some small enterprises or start-up teams. It is extremely hard for investors to acquire their information, so they will depend more on the information disclosure on crowdfunding platforms. When investors take the central route, the quality of project description is vital. The investigation on the issue information and issue rules on the global largest crowdfunding platform-Kickstarter found that description information could be divided into soft information and hard information. Hard information refers to the clear and objective information description, including product parameters, drafts, pictures, videos, and display of some finished parts. Soft information is the ambiguous text information, to which different people have different opinions.

Considering the uncertain feature of crowdfunding projects, Kickstarter sets the module of "risks and challenges" to require sponsors to disclose the foreseeable problems and challenges. After the investigation, the author found that disclosure information could be divided into two types. The first type is that sponsors classify and illustrate the foreseeable risks; the other one is that sponsors make the subjective warranty acceptance. The description must be foreseeable and subjective, which must be the concentrated area of soft information. For the investors who take the enter path, soft information, on the one hand, may give them some prompt information about risks. On the other hand, soft information could not provide the powerful evidence for the acceptance of sponsors. Therefore, soft information has negative influence on investment decision. The detailed degree of project description and the module classification are totally different for different types of projects. In order to measure the fuzzy degree of project introduction, the paper refers to the method that Tom et al. (2010) [13] adopted when studying the influences of fuzzy information about risk warning on the income of new stocks; takes the soft information in the module of risks and challenges on Kickstarter as the object to count the word number of text information in the model and the total word number of introduction on the display webpage. The paper measures the uncertainty degree of disclosure information through the proportion of the word number of soft information among the total word number of introduction, and proposes the following hypotheses.

H1: The uncertainty of crowdfunding projects has negative influence on decisions of the investors who choose the central route. The uncertainty degree of project introduction has a negative correlation with the success rate of financing.

For the investors who give up the central route and choose the peripheral route to make investment decisions, they pay close attention to edge clues. Peripheral route includes 6 clues: return, consistency, social proof, preference, authority, and scarcity (Hu Min, 2011) [14]. Investors tend to be extremely interested in projects before investing, so the effects of other clues except preference will be discussed here.

1) Social capital

Insistency, return, and social proof are closely linked with the social capital of sponsors.

Return refers to that a person will be likely to change his mind when owing someone. Some sponsors may invest other crowdfunding projects at the same time because they are interested in or they want to promote the diffusion of their own projects and to expand the influence. Investees feel that they are obligatory to support investors' projects, to promote successful financing of their own projects. Consistency and social proof mean that evidence is always being processed in the same way. Social proof can change one's mind because of the effect of crowd mentality (Hu Min, 2011). Investors and sponsors could communicate project information publically on the communication platform built by crowdfunding websites. Sponsors' explanation to investors' questions could be the referential information of other investors, which is favorable to success. Social capital reflects individual's social relations in community (Coleman, 1998) [15]. The paper refers to the method that Zheng et al. (2014) [16] adopted when studying the influences of the social capital of sponsors on crowdfunding perfor- 
mance to take sponsors' interaction times with others during financing period as the index of the relationoriented social capital of sponsors. Through the edge clues of return, the structure-oriented social capital influences investment decision; through the edge clues of consistency and social proof, the relation-oriented social capital influences investment decision.

H2: Through the peripheral route, sponsors' social capital influences investment decision, which has a positive correlation with the success rate of financing.

2) The third-party's authoritative comments

The persuasive power of authoritative approach could be like this: "I believe..., so you should..." (Hu Min, 2011). Many sponsors recognize that their description information is subjective, so they quote the positive comments on the third-party authoritative platforms to increase the persuasion.

H3: Through the peripheral route, authoritative information influences investment decision, which has a positive correlation with the success rate of financing.

\section{3) Scarcity}

Scarcity usually appears at the end of persuasion, because "you must make the decision before they leave" (Petty and Cacioppo, 1986). The threshold mechanism of crowdfunding platforms requires the financing should be completed within the limited time. At present, financing should be completed within 60 days on Kickstarter. Investors must make decisions within 60 days. Projects could arouse greater interest for more investors if the duration is longer, but these projects may leave an unconfident impression on investors. On the contrary, the shorter duration of project could show the confidence of sponsors. Therefore, the duration has influences on financing through its influence on investors' mind.

H4: The duration has negative correlation with the success rate of financing.

In summary, the theoretical framework of the research is shown in Figure 1.

\section{Data Collection and Variable Design}

In order to test the propositions and hypotheses above, collection and statistic analysis of the data of crowdfunding projects on Kickstarter is made to prepare for the following logistic regression analysis with the help of stata 12.0 .

\subsection{Data Collection and Instruction}

All project data in the paper comes from the global largest crowdfunding platform-Kickstarter, because: 1) Kickstarter collects the most outstanding crowdfunding projects in the word; it has the largest number of users, the most complete mechanism, and the most transparent information; 2) Relatively speaking, small teams could have more fair opportunities (Liu Wenhui, 2014) [16].

The data comes from the projects which were sponsored in China from 2009 to 22 May 2015. Except the projects whose fund is being raised and which were eliminated in the midway, the data of 261 projects which were sponsored in Chinese mainland and the data of 39 technology projects which were sponsored in Hong Kong (whose processing was done in mainland cities such as Shenzhen) was collected finally. Referring to the classification rules on Kickstarter, the paper divides these 300 projects into 11 types, including technology, food, animation, design, public welfare, entertainment, audio \& video, publish, game, art, and others.

Their distribution in Chinese mainland is shown in Figure 2 and Figure 3.261 projects distributed widely in mainland, covering 43 cities. The northernmost one was in Jiamusi of Heilongjiang; the westernmost one was in Lhasa of Tibet; the southernmost one was in Haikou of Hainan. From the perspective of number, most of them

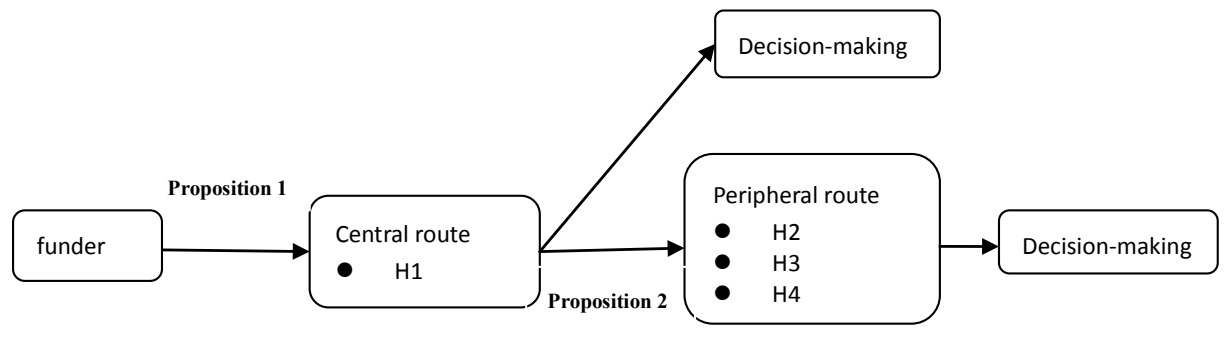

Figure 1. The theoretical framework of the research. 


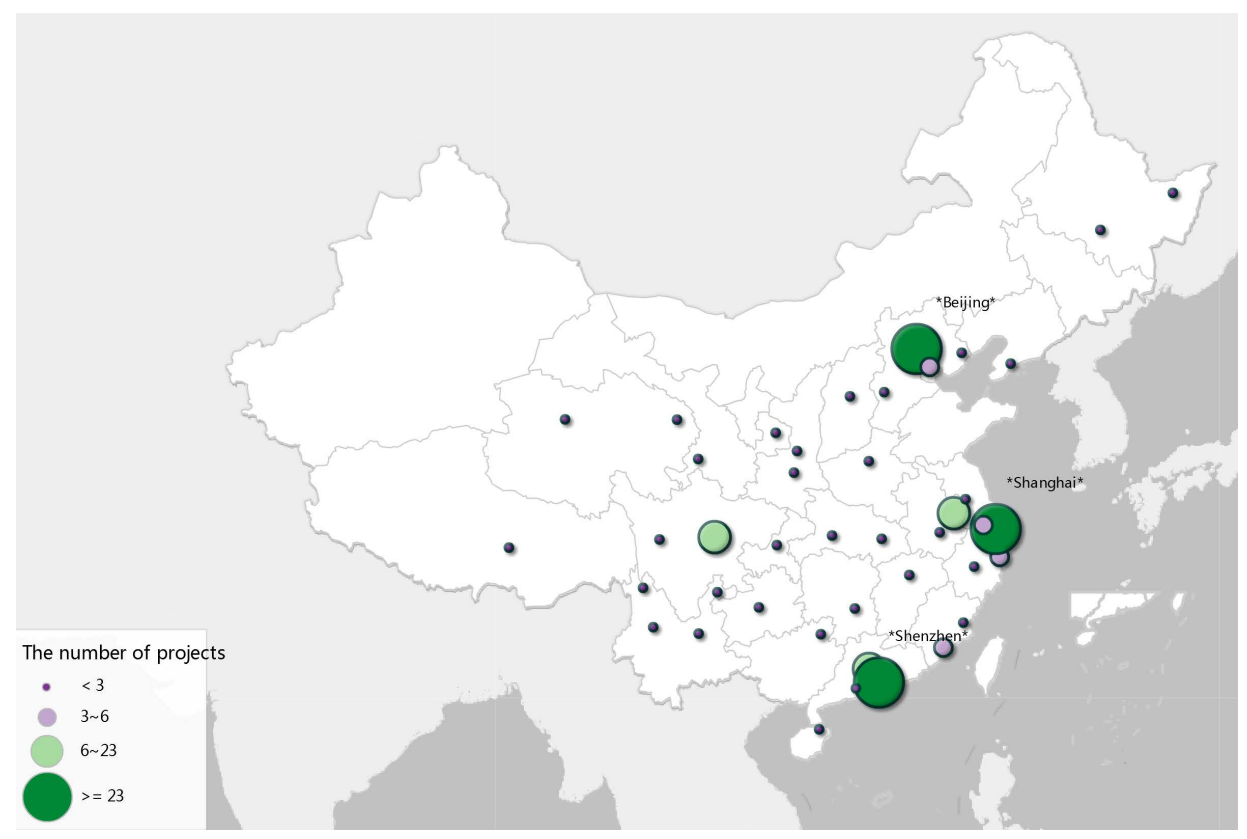

Figure 2. The distribution of the projects from mainland China on Kickstarter.

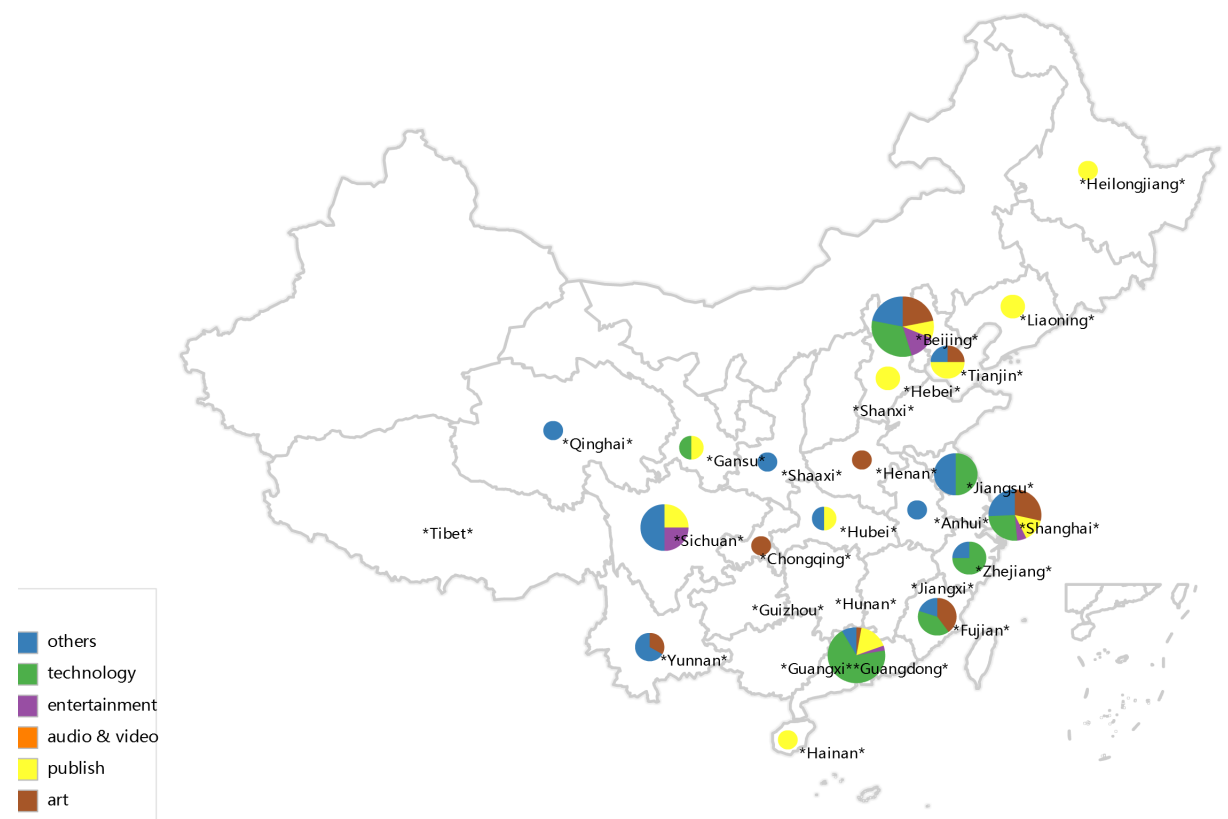

Figure 3. The structure of the projects from mainland China on Kickstarter.

concentrated on North China Plain, "Yangtze River Belt", and "Pearl River Belt". 90 projects were sponsored in Beijing, which occupied 34\%. 62 ones were sponsored in Shanghai, occupying 24\%. 23 projects and 11 projects were sponsored in Shenzhen and Guangzhou respectively, and 11 projects were sponsored in Chengdu.

\subsection{Variable Design}

The threshold mechanism "all or nothing" is adopted on Kickstarter. The crowdfunding will be a successful one if the fund reaches or exceeds the default amount within the duration. The logistic method is used to make regression analysis. Variable Definitions are displaced in Table 1. 
Table 1. Variable definitions.

\begin{tabular}{|c|c|}
\hline Variable & Definition \\
\hline Sf & Dummy variable indicates whether the project was successfully funded ( $1=$ success, $0=$ failure). \\
\hline Ratio & The ratio of the number of words of text information between "Risk \& Challenge" and the total project description. \\
\hline W_risks & $\begin{array}{l}\text { Dummy variable indicates whether the expected risk was pointed out by refined key words in the "Risk and Challenge" } \\
\text { board }(1=\text { yes, } 0=\text { no). }\end{array}$ \\
\hline Update & The number of updates reflect the latest progress of the project and the interactions between sponsors and investors. \\
\hline Backed & The number of times sponsor supports other projects as funder before the deadline of his/her project. \\
\hline Hudong & The number of times sponsor interacts with others during the period of project financing. \\
\hline Media & $\begin{array}{l}\text { Dummy variable indicates whether there is positive evaluation about the project from third-party authoritative media } \\
\text { platform }(1=\text { yes, } 0=\text { no). }\end{array}$ \\
\hline Days & Refers to the pre-set duration of project financing. \\
\hline Creator & Dummy variable indicates whether there is non-Chinese member in the team $(1=$ yes, $0=$ no $)$. \\
\hline Goal & The amount founders seek to raise using crowdfunding. \\
\hline Reward & The number of investment options set according to different levels of reward. \\
\hline
\end{tabular}

1) Dependent variable

The crowdfunding result is a virtual variable. 1 represents the successful financing, and 0 represents the failed one.

2) Independent variables

On the measurement of uncertainty degree of project, the independent variable-fuzzy degree of project information is the ratio of the word number of text information in the module of "risks and challenges" among the total word number of project information, which presents the ratio of soft information in project description information. The times of dynamic update represents sponsor's effort when overcoming information asymmetry. The disclosure of risk type represents that whether sponsors point out the foreseeable risks with key words in the module of risk and challenges. The times that sponsors invest other projects represent sponsors' structureoriented social capital. The times of financing interaction represents sponsors' relation-oriented social capital. The other two independent variables are financing duration and virtual independent variable (whether there are positive comments from the third-party authoritative platforms).

3) Controlled variable

The clear classification of return is favorable for sponsors to implement the price discrimination strategy to make more funds and profits (Hardy, 2013) [17], and will stimulate investors to make multiple choices. Therefore, the investment amount type that investors set according to different return contents is chosen as the controlled variable.

Human capital such as number of employees and number of shareholders can measure the comprehensive strength and quality of start-up teams. The data comes from Chinese projects, so whether team members have international background should be considered.

\subsection{Descriptive Statistics}

Table 2 is the descriptive statistics about the sample data. The data shows that $51 \%$ of crowdfunding projects on the platform were successful ones. The average default financing amount of the sample was 32,646.03 yuan. The expected financing goal of the successful ones was lower than that of the failed ones $(17,582.95$ yuan vs $48,323.94$ yuan). Investors could have 8 choices of return on the platform for each project. The financing could be completed within 35 days on the average. It could be seen that creative crowdfunding platforms provide the brand new financing channel for small projects.

The data shows that the fuzzy information occupied about $15 \%$ in description information, and the ratio of the fuzzy information in the successful ones was lower than that of the failed ones $(10 \% \mathrm{vs} 20 \%)$. The difference of $\mathrm{t}$ value was significant, which reflects that the high degree of uncertainty has negative influence on investment decision. On the contrary, the times of update in the successful projects was much higher than that of the failed 
Table 2. Descriptive statistics.

\begin{tabular}{cccccccc}
\hline \multirow{2}{*}{ Variable } & \multicolumn{2}{c}{ All } & \multicolumn{2}{c}{ Failure } & Success & T-value \\
\cline { 2 - 6 } & 0bs & Mean & Min & Max & Mean & Mean & - \\
Sf & 300 & 0.51 & 0 & 1 & 0 & 1 & $5.2740^{* * *}$ \\
Ratio & 300 & 0.146638 & 0 & 0.895238 & 0.1977412 & 0.0975392 & 0.8484 \\
W_Risks & 300 & 0.5533333 & 0 & 1 & 1.57732 & 1.514851 & $-7.4086^{* * *}$ \\
Update & 300 & 5.586667 & 0 & 94 & 1.843537 & 9.183007 & $-4.0714^{* * *}$ \\
Backed & 300 & 4.706667 & 0 & 89 & 2.435374 & 6.888889 & $-5.8697^{* * *}$ \\
Hudong & 300 & 17.42667 & 0 & 387 & 1.190476 & 33.02614 & $-3.5832^{* * *}$ \\
Media & 300 & 0.298658 & 0 & 1 & 0.2040816 & 0.3907285 & 1.6296 \\
Days & 300 & 34.96 & 2 & 91 & 36.05442 & 33.9085 & 0.0318 \\
Creator & 288 & 0.7048611 & 0 & 1 & 0.7092199 & 0.707483 & 1.1159 \\
Goal & 300 & 32646.03 & 100 & $4,000,000$ & 48323.94 & 17582.95 & $-4.6736^{* * *}$ \\
Reward & 300 & 8.746667 & 1 & 42 & 7.278912 & 10.15686 & 153 \\
Obs & & 300 & & & 147 & - \\
\hline
\end{tabular}

ones ( 10 vs 20$)$. The result shows that the effort that sponsors overcome information asymmetry has positive influence on investment decision, which proves Proposition 1 and H1. The data also shows that the communication between sponsors and investors was less frequent in the failed projects (twice on the average), but the communication in the successful projects was frequent (33 times on the average). The difference of $t$ value was significant, which shows that sponsors pay more attention to using the internal community built by crowdfunding platforms to accumulate the social capital when considering the special features of crowdfunding products, and it has positive influence on the investors who choose the peripheral route, which provides some evidence for Proposition 2 and $\mathrm{H} 2$.

\section{Regression Analysis}

\subsection{Correlation Analysis}

In order to make the data features conform to the requirements of regression, logarithmic processing is done to the default amount, which is represented with in goal. The standardized processing is done to the times of update and the times of interaction, which are represented with z2update and z2hudong. The Pearson correlation between the explanatory variables and the explained variables is analyzed at first. The result is shown in Table 3 .

The multicollinearity test is made on all variables with the help of the cold diag 2 in stata 12.0. The condition value is $28.62(<30)$, which shows that there is no colinearity relation among all variables.

\subsection{The Estimated Results and Explanation}

The logistic regression analysis is made on the model with the help of stata 12.0. The results could be seen in Table 4 and Table 5.

In order to explore whether the regression results are reliable, the robust test is made on the estimation results, and the regression results and the robust test results are compared then. The comparison results are: the likelihood functions and R2 in the two models do not change. From the perspective of the estimated coefficients of the explanatory variables, the change of the estimated coefficients is slight. From the perspective of the significant level of the explanatory variables, the independent variable (the times that sponsors invest other projects) has an insignificant correlation in Model 5 (which had a significant correlation at 5\% level); the controlled variable (the source of team members) has an insignificant correlation now (which had a significant correlation at $10 \%$ level). In summary, the regression results are reliable. 
Table 3. Pearson correlation.

\begin{tabular}{ccc}
\hline Variable & Correlation Coefficient & Significance \\
\hline Ratio & $-0.2922^{* * * *}$ & 0.0000 \\
W_Risks & -0.0491 & 0.3969 \\
z2Update & $0.3944^{* * *}$ & 0.0000 \\
Backed & $0.2296^{* * *}$ & 0.0001 \\
z2Hudong & $0.3219^{* * *}$ & 0.0000 \\
Media & $0.2039^{* * *}$ & 0.0004 \\
Days & -0.0940 & 0.1042 \\
Creator & -0.0019 & 0.9747 \\
In_Goal & -0.0272 & 0.6393 \\
Reward & $0.2613^{* * *}$ & 0.0000 \\
\hline
\end{tabular}

Table 4. Regression result.

\begin{tabular}{|c|c|c|c|c|c|}
\hline \multirow{2}{*}{ Variable } & (1) & (2) & (3) & (4) & (5) \\
\hline & Model 1 & Model 2 & Model 3 & Model 4 & Model 5 \\
\hline \multirow[t]{2}{*}{ Ratio } & $-2.374^{* * *}$ & & & $-1.635^{*}$ & $-2.153^{* *}$ \\
\hline & $(-2.71)$ & & & $(-1.78)$ & $(-2.10)$ \\
\hline \multirow[t]{2}{*}{ W_Risks } & -0.422 & & & $-0.560^{*}$ & $-0.654^{* *}$ \\
\hline & $(-1.56)$ & & & $(-1.94)$ & $(-2.02)$ \\
\hline \multirow[t]{2}{*}{ z2Update } & $1.784^{* * *}$ & & & $1.100^{* * *}$ & $1.586^{* * *}$ \\
\hline & $(5.72)$ & & & $(2.85)$ & $(3.45)$ \\
\hline \multirow[t]{2}{*}{ z2Hudong } & & $5.309^{* * *}$ & $6.957^{* * *}$ & $3.291^{* *}$ & $4.279^{* * *}$ \\
\hline & & (3.96) & $(4.29)$ & (2.49) & (2.64) \\
\hline \multirow[t]{2}{*}{ Days } & & $-0.031^{* *}$ & -0.016 & $-0.041^{* * *}$ & $-0.031^{*}$ \\
\hline & & $(-2.36)$ & $(-1.16)$ & $(-2.73)$ & $(-1.85)$ \\
\hline \multirow[t]{2}{*}{ Backed } & & $0.062^{* * *}$ & $0.061^{* * *}$ & $0.047^{* *}$ & $0.047^{* *}$ \\
\hline & & $(2.79)$ & $(2.60)$ & $(2.24)$ & $(2.01)$ \\
\hline \multirow[t]{2}{*}{ Media } & & $0.771^{* *}$ & $0.845^{* *}$ & 0.498 & 0.579 \\
\hline & & $(2.52)$ & $(2.51)$ & (1.53) & $(1.58)$ \\
\hline \multirow[t]{2}{*}{ Creator } & & & $0.843^{* *}$ & & $0.655^{*}$ \\
\hline & & & $(2.34)$ & & (1.68) \\
\hline \multirow[t]{2}{*}{ Reward } & & & $0.088^{* *}$ & & $0.074^{* *}$ \\
\hline & & & $(2.57)$ & & $(2.06)$ \\
\hline \multirow[t]{2}{*}{ ln_Goal } & & & $-0.645^{* * *}$ & & $-0.861^{* * *}$ \\
\hline & & & $(-4.60)$ & & $(-5.34)$ \\
\hline \multirow[t]{2}{*}{ Constant } & $0.896^{* * *}$ & $1.956^{* * *}$ & $6.101^{* * *}$ & $2.640^{* * *}$ & $9.071^{* * *}$ \\
\hline & (3.59) & $(2.95)$ & $(4.51)$ & $(3.71)$ & $(5.58)$ \\
\hline$N$ & 300 & 298 & 286 & 298 & 286 \\
\hline Chi2 & 88.63 & 98.80 & 122.18 & 117.38 & 146.53 \\
\hline $\mathrm{P}$ & 0.0000 & 0.0000 & 0.0000 & 0.0000 & 0.0000 \\
\hline Pseudo R2 & 0.2132 & 0.2392 & 0.3082 & 0.2842 & 0.3696 \\
\hline
\end{tabular}

\footnotetext{
${ }^{* * *} \mathrm{p}<0.01,{ }^{* *} \mathrm{p}<0.05,{ }^{*} \mathrm{p}<0.1$.
} 
Table 5. Robust regression results.

\begin{tabular}{|c|c|c|c|c|c|}
\hline \multirow{2}{*}{ Variable } & (1) & (2) & (3) & (4) & (5) \\
\hline & Model 1 & Model 2 & Model 3 & Model 4 & Model 5 \\
\hline \multirow[t]{2}{*}{ Ratio } & $-2.374^{* *}$ & & & $-1.635^{*}$ & $-2.153^{* *}$ \\
\hline & $(-2.57)$ & & & $(-1.75)$ & $(-2.24)$ \\
\hline \multirow[t]{2}{*}{ W_Risks } & -0.422 & & & $-0.560^{* *}$ & $-0.654^{* *}$ \\
\hline & $(-1.61)$ & & & $(-1.97)$ & $(-2.08)$ \\
\hline \multirow[t]{2}{*}{ z2Update } & $1.784^{* * *}$ & & & $1.100^{* *}$ & $1.586^{* *}$ \\
\hline & $(4.21)$ & & & $(2.01)$ & $(2.22)$ \\
\hline \multirow[t]{2}{*}{ z2Hudong } & & $5.309^{* *}$ & $6.957^{* * *}$ & $3.291^{*}$ & $4.279^{*}$ \\
\hline & & $(2.63)$ & $(2.59)$ & $(1.85)$ & (1.73) \\
\hline \multirow[t]{2}{*}{ Days } & & $-0.031^{* * *}$ & -0.016 & $-0.041^{* * *}$ & $-0.031^{* *}$ \\
\hline & & $(-2.63)$ & $(-1.34)$ & $(-2.91)$ & $(-1.98)$ \\
\hline \multirow[t]{2}{*}{ Backed } & & $0.062^{* *}$ & $0.061^{*}$ & $0.047^{* *}$ & 0.047 \\
\hline & & $(2.25)$ & $(1.88)$ & (2.13) & $(1.46)$ \\
\hline \multirow[t]{2}{*}{ Media } & & $0.771^{* *}$ & $0.845^{* * *}$ & 0.498 & 0.579 \\
\hline & & $(2.57)$ & $(2.63)$ & $(1.57)$ & (1.63) \\
\hline \multirow[t]{2}{*}{ Creator } & & & $0.843^{* *}$ & & 0.655 \\
\hline & & & (2.18) & & $(1.53)$ \\
\hline \multirow[t]{2}{*}{ Reward } & & & $0.088^{* * *}$ & & $0.074^{* *}$ \\
\hline & & & (3.15) & & $(2.61)$ \\
\hline \multirow[t]{2}{*}{ ln_Goal } & & & $-0.645^{* * *}$ & & $-0.861^{* * *}$ \\
\hline & & & $(-4.82)$ & & $(-5.61)$ \\
\hline \multirow[t]{2}{*}{ _Cons } & $0.896^{* * *}$ & $1.956^{* *}$ & $6.101^{* * *}$ & $2.640^{* * *}$ & $9.071^{* * *}$ \\
\hline & $(3.65)$ & $(2.25)$ & (4.04) & $(3.24)$ & $(5.27)$ \\
\hline$N$ & 300 & 298 & 286 & 298 & 286 \\
\hline Chi2 & 34.72 & 25.69 & 36.86 & 43.17 & 51.14 \\
\hline $\mathrm{P}$ & 0.0000 & 0.0000 & 0.0000 & 0.0000 & 0.0000 \\
\hline Pseudo R2 & 0.2132 & 0.2392 & 0.3082 & 0.2842 & 0.3696 \\
\hline
\end{tabular}

${ }^{* * *} \mathrm{p}<0.01,{ }^{* *} \mathrm{p}<0.05,{ }^{*} \mathrm{p}<0.1$.

The results of Model 1 show that the fuzzy degree of project information has a negative correlation with the success rate of financing, and it is significant at 5\% level. The times of update and the success rate of financing have a positive correlation, and it is significant at $1 \%$ level. The results reflect that for the investors who directly choose the central route in decision, the higher the fuzzy degree of projection information is, the more unfavorable the elaboration processing and the investment decision will be. On the contrary, the frequent update not only could reduce investors' confusion properly, but also could show sponsors' active attitude for solving the problem of information asymmetry, which has positive influence on investment decision. The results prove Proposition 1 and $\mathrm{H} 1$.

The results of Model 2 show that the times of interaction, the times that sponsors invest other projects, and the third-party authoritative comments have a positive correlation with the success rate of financing, and it is signif- 
icant at $5 \%$ level. The duration has a negative correlation with the success rate of financing, and it is significant at $1 \%$ level. The results reflect that the edge clues provided by sponsors will play an important role in investment decision when investors give up the central route and adopt the peripheral route. Investors' questions when browsing projects could be answered when sponsors and other potential investors talk about the relevant problems. In addition, investors could communicate with sponsors directly to resolve their doubts. Sponsors build their own social capital in the internal community by interacting with investors and investing other projects, which will promote the successful financing. In addition, the comments of the third-party authoritative platforms could play an important role in project diffusion. If the duration is longer, it will have negative influence on financing because sponsors will leave an unconfident impression on investors, which is similar with the previous research results.

The results of Model 3 show that the international background of team member and the different types of return have a positive correlation with the successful rate of financing, and they are significant at the level of 5\% and $1 \%$ respectively. The financial goal has a negative correlation with the successful rate of financing, and it is significant on the level of $1 \%$. The results reflect that investors tend to refer to the information about sponsor teams when paying attention to the edge information. As a global crowdfunding platform, Kickstarter covers projects in the whole world, so investors' own conceptions may influence their judgment. Take the smart hardware technology projects which were sponsored in China as an example. As the "world plant", China's manufacturing cost is low. But China leaves the impressions of weak innovation ability and knock-off overflow. For the investors who worry about the quality, the international background of Chinese crowdfunding projects is an advantage, which can promote the successful financing. In addition, the clear classification of return can project the successful financing as well. The higher the financial goal is, the lower the rate of success will be, which conforms to the expected regression result. Proposition 2, H2, H3, and $\mathrm{H} 4$ are proved.

The results of Model 4 and Model 5 show that under the circumstance when the edge information is considered, the uncertainty degree still has a significant influence on the success rate of financing. The key-word prompt information provided by sponsors is unfavorable to the success of financing, which does not conform to the expected result because the clear foreseeable risks reflect that sponsors prepare well about projects and are sincere to investors. Through the concrete analysis on the relevant content in the sample, the author found that for the reasons of the special features of crowdfunding projects and sponsors' subjective choice, most of explanations are sponsors' acceptance contents according to their relevant dealing experience. For the investors without rich experience, such action is only risk prompt information, so they will doubt the investment, which will have negative influence on financing. The fuzzy degree of project information has a negative correlation with the success rate of financing, and the times of update has a positive correlation with the success rate of financing, which are significant at 5\% level. The significant level between the positive correlation of the times of interaction and the success rate of financing reduces to $10 \%$, and the significant level of other edge information reduces or the correlation turns to insignificant, which shows that for the investors who take the central route to do elaboration processing and takes the edge clues into consideration, uncertainty factors still have significant influence on investment decision. Relatively, the effect of edge information weakens.

\section{Conclusions}

The results of the theoretical and empirical analysis show that investors tend to take the central route to do elaboration processing and refer to edge clues to make decision.

The investors with weaker cognitive ability and less relevant knowledge will pay more attention to other edge information apart from project descriptive information. The social capital sponsors built in the internal community will promote the success of financing. In addition, quoting the positive comment on the authoritative information platforms in relevant fields is also favorable to the diffusion of projects. Sometimes investors judge projects according to their experience and opinion, which is reflected in investors' evaluation to the features of the sponsor team members in the paper. For China, the developing manufacturing power, the teams with international background are more likely to meet the needs of international market, which will have positive influence on financing.

For the investors who take the central route to do information elaboration processing and refer to edge clues, uncertainty factors still have significant influences on them when making decisions. Relatively, the effect of edge information weakens. It reflects that compared with ordinary consumers, these investment-oriented consumers are more interested in crowdfunding products and are willing to undertake risks, but they will still make 
rational investment decisions finally.

\section{References}

[1] Mollick, E. (2012) The Dynamics of Crowdfunding: Determinants of Success and Failure. Social Science Research Network Scholarly Paper No. 2088298.

[2] Zeng, J.H. and Gan, X.Y. (2014) Empirical Research on Effect of Social Capital on Success Rate of Crowdfunding Project. Technology Economic, 33, 90-115.

[3] Gerber, E.M., Hui, J.S. and Kuo, P.Y. (2012) Crowdfunding: Why People Are Motivated to Post and Fund Projects on Crowdfunding Platforms.

http://www.researchgate.net/Publication/261359489_Crowdfunding_Why_People_are_Motivated to_Post_and_Fund Projects on_Crowdfunding_Platforms

[4] Agrawal, A., Catalini, C. and Goldfarb, A. (2013) Some Simple Economics of Crowdfunding. National Bureau of Economic Research Working Paper No. 19133.

[5] Huang, L. and Zhou, Q. (2014) Study on Heterogeneity of Financing Incentives and Self-Feedback Mechanism in Creative Crowdfunding: The Case of the "Demohour". China Industrial Economics, 7, 135-147.

[6] Giudici, G., Nava, R., Rossi Lamastra, C., et al. (2012) Crowdfunding: The New Frontier for Financing Entrepreneurship? Social Science Research Network Scholarly Paper No. 2157429.

[7] Agrawal, A., Catalini, C. and Goldfarb, A. (2011) The Geography of Crowdfunding. National Bureau of Economic Research Working Paper No. 16820.

[8] Mollick, E. (2014). The Dynamics of Crowdfunding: An Exploratory Study. Journal of Business Venturing, 29, 1-16. http://dx.doi.org/10.1016/i.jbusvent.2013.06.005

[9] Petty, R.E. and Cacioppo, J.T. (1986) The Elaboration Likelihood Model of Persuasion. Advances in Experimental Social Psychology, 19, 123-205. http://dx.doi.org/10.1016/S0065-2601(08)60214-2

[10] Martin, R. and Hewstone, M. (2010) Minority Influence and Innovation: Antecedents, Processes, and Consequences. Psychology Press, London, 105-131.

[11] Li, Z. and Ma, J. (2006) Advertisement and Theoretical Elaboration Likelihood Model. Press Circles, 2, 101-102.

[12] Agrawal, A., Catalini, C. and Goldfarb, A. (2015) Crowdfunding: Geography, Social Networks, and the Timing of Investment Decisions. Journal of Economic \& Management Strategy, 24, 253-274. http://dx.doi.org/10.1111/jems. 12093

[13] Arnold, T., Raymond, P., Fishe, H. and North, D. (2010) The Effects of Ambiguous Information on Initial and Subsequent IPO Returns. Financial Management, 2010, 1497-1519. http://dx.doi.org/10.1111/j.1755-053X.2010.01120.x

[14] Hu, M. (2011) Pattern of Online Customers' Behavior: from the Perspective of ELM Theory. Master Thesis, Zhejiang University, Hangzhou.

[15] Coleman, J.S. (1998) Social Capital in the Creation of Human Capital. American Journal of Sociology, 94, 95-120. http://dx.doi.org/10.1086/228943

[16] Liu, W.H. (2014) The Influence of Kickstarter in China. 21st Century Business Review, 16, 64-65.

[17] Hardy, W. (2013) How to Perfectly Discriminate in a Crowd? A Theoretical Model of Crowdfunding, Working Paper. 